\title{
Jugular Anomalies in Multiple Sclerosis Are Associated with Increased Collateral Venous Flow
}

\author{
(D) S.K. Sethi, (D) A.M. Daugherty, DG. Gadda, DD.T. Utriainen, (D). Jiang, N. N. Raz, and (DE.M. Haacke
}

\begin{abstract}
BACKGROUND AND PURPOSE: To date, research on extracranial venous collaterals has been focused on structure, with relatively little attention paid to hemodynamics. We addressed this limitation by quantitatively comparing collateral flow in patients with multiple sclerosis and healthy controls by using phase-contrast MR imaging. We hypothesize that patients with MS with structurally anomalous internal jugular veins will have elevated collateral venous flow compared with healthy controls.
\end{abstract}

MATERIALS AND METHODS: The sample consisted of 276 patients with MS and 106 healthy controls. We used MRV to classify internal jugular veins as stenotic and nonstenotic based on an absolute cross-sectional area threshold in 276 patients with MS and 60 healthy controls; 46 healthy controls lacked this imaging. Individual and total vessel flows were quantified by using phase-contrast MR imaging on all patients. Veins were classified by extracranial drainage type: internal jugular veins (I), paraspinal (II), and superficial (III). Differences among healthy controls, patients with MS, nonstenotic patients, and stenotic subgroups in total venous flow by vessel type were evaluated in a general linear model for statistical analysis.

RESULTS: In the MS group, 153 patients (55\%) evidenced stenosis, whereas $12(20 \%)$ healthy controls were classified as stenotic $(P<.001)$. Compared with healthy controls, the MS group showed lower type I flow and increased type II flow. Stenosis was associated with reduced flow in the type I vessels $[F(1272)=68 ; P<.001]$. The stenotic MS group had increased flow in the type II vessels compared with the nonstenotic MS group $[F(1272)=67 ; P<.001]$.

CONCLUSIONS: Compared with healthy controls, patients with MS exhibit reduced venous flow in the main extracerebral drainage vein (internal jugular vein). In contrast, flow in the paraspinal venous collaterals is elevated in patients with MS and exacerbated by venous stenosis. Collateral drainage may be a compensatory response to internal jugular vein flow reduction.

ABBREVIATIONS: CSA = cross-sectional area; $\mathrm{HC}=$ healthy control; $\mathrm{JV}=$ internal jugular vein; $\mathrm{PC}=$ phase-contrast

M ultiple sclerosis is an inflammatory, demyelinating disease of the CNS. The exact origin remains elusive, though epidemiologic studies have shown that it is multifactorial and likely caused by an interaction between environmental and genetic factors. ${ }^{1}$ Although autoimmune etiology is the current consensus, a recent vascular hypothesis of MS suggested chronic cerebrospinal venous insufficiency as a major culprit. The chronic cerebrospinal

Received January 15, 2017; accepted after revision March 13.

From The MRI Institute for Biomedical Research (S.K.S., D.T.U., J.J., E.M.H.), Detroit, Michigan; Institute of Gerontology (A.M.D., N.R.) and Departments of Psychology (N.R.) and Radiology (E.M.H.), Wayne State University, Detroit, Michigan; and Department of Physics and Earth Sciences (G.G.), University of Ferrara, Ferrara, Italy.

This work was supported in part by a grant from the National Institute on Aging, R37-AG011230 to Dr. Naftali Raz.

Please address correspondence to Sean K. Sethi, MS, 440 E. Ferry St \#1, The MRI Institute for Biomedical Research, Detroit, MI 48202; e-mail: sethisea@gmail.com

- Indicates open access to non-subscribers at www.ajnr.org

http://dx.doi.org/10.3174/ajnr.A5219 venous insufficiency hypothesis postulates that abnormalities in the structure and hemodynamics of intracranial and extracranial veins may induce MS symptoms. Initial research on chronic cerebrospinal venous insufficiency used Doppler sonography and catheter venography to quantify flow and visualize vascular anatomy, respectively. Since then, however, several attempts to validate the initial findings yielded mixed results. The lack of standardized image modalities and analytic methods, as well as low statistical power, may explain the discrepant conclusions. ${ }^{2,3}$

MR imaging, unlike ultrasonography, is an operator-independent method that can detect demyelinating and iron-laden lesions in the brain parenchyma and confirm the MS diagnosis. The advantages of MR imaging, in addition to lesion detection, are the abilities to rapidly generate a $3 \mathrm{D}$ map of the vasculature by using venography and to quantify blood flow in large and small extracranial blood vessels by using phase-contrast (PC) flow quantification. These methods have been already successfully applied 


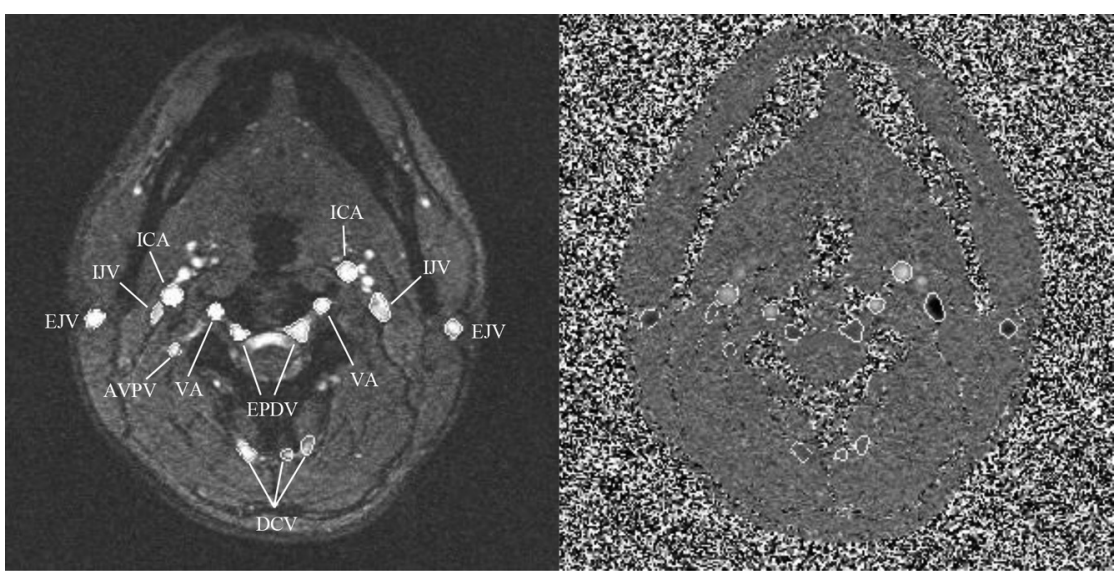

FIG 1. PC-MR imaging magnitude (left) and phase (right) images showing the neck level for a healthy patient. Artery and vein contours were traced on the images semiautomatically; arteries appear bright, whereas veins appear dark on phase images. Type I veins: IJV; type II veins: AVPV: anterior venous plexus vein; EPDV: epidural vein; DCV, deep cervical vein; type III veins: EJV, external jugular vein. Arteries: ICA; VA, vertebral artery.

to detecting vascular and flow abnormalities in the internal jugular vein (IJV) in healthy older adults ${ }^{4}$ and within a subset of patients with MS. ${ }^{3,5-7}$

Research on venous abnormalities in MS thus far has been limited to the IJV, and little is known about extracranial venous collateralization. The extrajugular drainage system consists of the vertebral venous system; the deep cervical veins, which anatomically are paraspinal toward the heart; and the anterior and external jugular veins, which receive blood from facial and superficial areas. ${ }^{8}$ Although the presence and structure of collateral veins have been assessed by using time-resolved imaging of contrast kinetics venography, flow values were not quantitatively evaluated. ${ }^{9-11}$ The purpose of this work was to examine the relation of extracranial venous anatomy and flow in a large cohort of patients with MS and healthy controls (HCs) taken from our neuroimaging data base. ${ }^{12}$ Because of the complexity of the extracranial venous system, we have classified these vessels into 3 groups based on anatomic MR information and their drainage path: primary (ie, IJV), paraspinal, and superficial. We hypothesized that increased venous paraspinal and superficial flow will also be observed for cases that evidence abnormal IJV structure and flow. In contrast, a subset of patients with MS may have a distinct collateral venous flow pattern compared with patients with MS and HCs without structural venous anomalies.

\section{MATERIALS AND METHODS \\ Participants}

The sample consisted of 276 patients with MS (194 women; mean, 48.8 years; SD, 10.9 years) and 106 HCs ( 58 women; M, 42.4 years; SD, 15.4 years). The patients with MS were classified into 3 types: relapsing-remitting $(n=157)$, primary-progressive $(n=30)$, and secondary-progressive $(n=39)$, whereas 50 patients did not have a known subtype. Patients with MS were excluded if they had a history of hypertension, previous vascular intervention, or presence of hypercoagulable state. Pregnant women and patients with cognitive impairment who were incapable of signing an informed consent form were also excluded. HCs were excluded if they had a history of diabetes, chronic renal disease, psychiatric or neuro- logic disorder, or substance abuse. All patients with MS and HCs with any contraindicated implant(s) were not included in this study.

\section{Data Acquisition}

All data were collected under Health Insurance Portability and Accountability Act guidelines and institutional review board approval. 3D contrast-enhanced MRV and 2D TOF MRV were used to assess the anatomy of the extracranial vessels on all patients with MS and 60 HCs because 46 of the 106 HCs lacked this imaging. Blood flow was quantified with PC-MR imaging at the C2-C3 cervical level for all patients with MS and HCs. Data from patients with MS were collected from 2 sites by using a 3T Trio Scanner (Siemens, Erlangen, Germany), ${ }^{3,7}$ and HC images were acquired on a 3T Verio scanner (Siemens) ${ }^{4}$ at the MR Research Facility at Wayne State University. On both scanners, a 16-channel head/neck coil arrangement was used. Imaging parameters and inclusion/exclusion criteria have been described in a previous publication. $^{7}$

\section{Image Processing and Analysis}

All data were processed and reviewed retrospectively with Signal Processing In Nuclear MR software (SPIN; MR Imaging Institute for Biomedical Research, Detroit, Michigan). Two raters evaluated MRV (3D time-resolved imaging of contrast kinetics or 2D TOF MRV if available) to assess stenosis of the IJVs in all samples by using established methods. ${ }^{7}$ Patients were classified as stenotic if the IJV met the following stenosis criteria: if the cross-sectional area (CSA) was less than $25 \mathrm{~mm}^{2}$ at the segment caudal to the $\mathrm{C} 3$ vertebral level and less than $12.5 \mathrm{~mm}^{2}$ at the segment cranial to the C3 vertebral level. ${ }^{3,7}$ Atretic or aplastic IJVs that showed no signal on venography were also categorized as stenotic. The cutoff of 25 $\mathrm{mm}^{2}$ was chosen assuming $70 \%$ stenosis in an IJV diameter of 1 cm. ${ }^{13,14}$ Discernable arterial and venous structures that flow to and from the cerebrum were identified and subtyped by using venography and PC flow sequences.

PC flow sequences were processed by 3 raters who were blinded to participants' characteristics. Vessels were demarcated by using an intensity threshold-based method, with manual tracing if necessary (Fig 1). Boundaries for each vessel were checked on the PC magnitude and phase maps. A list of vessels that were traced for each cervical level is given in the Table. Flow rates $(\mathrm{mL} / \mathrm{s})$ were calculated based on integrated flow velocities within the vessel lumen. Velocities that exceeded $50 \mathrm{~cm} / \mathrm{s}$ were unwrapped by SPIN software by using a robust automatic unwrapping algorithm that compares pixel-wise phase values in the $\mathrm{x}, \mathrm{y}$, and $\mathrm{z}$ directions and ensures that only pixels that are aliased are unwrapped. ${ }^{15}$

Venous structures were classified by drainage mode into 3 types (Table): type I, IJV; type II, paraspinal veins; and type III, superficial veins. For all statistical analyses, total venous flows, 


\begin{tabular}{llll}
\hline Venous Type I (Primary) & \multicolumn{1}{c}{ Venous Type II (Paraspinal) } & Venous Type III (Superficial) & Arteries \\
\hline Internal jugular veins & Deep cervical veins & External jugular veins & Vertebral arteries \\
& Vertebral veins & Anterior jugular veins & Internal carotid arteries \\
& Epidural veins & Posterior external jugular veins & \\
& Anterior vertebral venous plexus veins & & \\
& Posterior vertebral venous plexus veins & & \\
\hline
\end{tabular}

which is the bilateral sum of all included vessels within a vessel type, were used for each type.

\section{Statistical Methods}

Individual and group differences in flow measured in the 3 vessel types were assessed within a general linear model framework. Flow at the C2-C3 cervical level served as the dependent variable; age and sex were entered as covariates. First, we gauged the differences in flow between 2 diagnostic groups (group, patients with MS versus HCs) across 3 vessel types, with vessel type being a within-patient variable and group being a between-patient variable. A full model that included all interactions was tested first, and nonsignificant interactions were removed before evaluating a reduced model. All significant interactions were decomposed by using post hoc analyses of simple effects. For all statistical analyses, we used SYSTAT 13.0 (Systat Software, San Jose, California).

Before data processing, interrater reliability in assessing flow volume per cardiac cycle ( $\mathrm{mL} / \mathrm{CDC}$ ) was tested by using an intraclass correlation coefficient-2 statistic that assumes random raters. ${ }^{16}$ Total vessel flow for the ICA, vertebral artery, and IJV, as well as their sum (right + left) vessel flow, were tested in prior studies of patients with $\mathrm{MS}^{3}$ and healthy adults. ${ }^{4}$ For this study, we evaluated the reliability of total cerebral blood flow values (ICA + vertebral artery for the C2-C3 neck level), as well as total type II and III venous flow indicators. All rater pairs met a reliability of intraclass correlation coefficient-2 $>0.9$ for vessel totals. Agreement between raters for anatomic assessment was calculated by using a Cohen $\kappa$ statistic from a sample of 15 patients with MS and 15 HCs. The raters had an agreement of 0.87 . For Cohen $\kappa$, we considered values above 0.75 as excellent, values of $0.40-0.75$ as modest, and values below 0.40 as low.

\section{RESULTS}

\section{Anatomic Assessment}

Among patients with MS, 153 (60\%) had venous stenosis. No age differences between the groups were found $(P=.84)$. Stenosis was more prevalent among men $(59 / 82 ; 72 \%)$ than women (94/194; $48 \% ; P<.001$ ). Among HCs, only 60 (M, 37.9 years; SD, 10.9 years) were evaluated for stenosis because of a lack of anatomic venography imaging data (2D TOF MRV and $3 \mathrm{D}$ contrast enhanced MRA) on the remaining $46 \mathrm{HCs}$. Stenosis was identified in $12 \mathrm{HCs}(20 \%, 5$ men and 7 women; $P=.24)$.

\section{Differences in Flow between Diagnostic Groups and among Vessel Types}

Small age differences were noted in venous flow $[F(1378)=15.92$; $P<.001]$; significance was reached only for type 1 vessels $(r=$ $-0.13 ; P=.015)$. Neither sex- nor group-related differences were found (both main effects, $F<1$ ). However, a significant vessel $\times$ group interaction was observed $[F(2756)=23 ; P<.001]$. De- composition of that interaction into simple effects revealed greater flow in type I vessels among HCs compared with patients with MS [8.43 $\pm .27 \mathrm{~mL} / \mathrm{s}$ versus $7.32 \pm 0.18 \mathrm{~mL} / \mathrm{s} ; F(1378)=12$; $P=.001]$ and lesser flow in type II vessels for HCs compared with patients with MS $[0.70 \pm .17 \mathrm{~mL} / \mathrm{s}$ versus $2.11 \pm 0.11 \mathrm{~mL} / \mathrm{s}$; $F(1378)=49 ; P<.001]$. No flow differences in type III vessels were observed between the HCs and the patients with MS [1.22 \pm $0.70 \mathrm{~mL} / \mathrm{s}$ versus $1.40 \pm 0.11 \mathrm{~mL} / \mathrm{s} ; F(1378)=2.0$; no significance]. Fig 2 shows the mean total flows by venous drainage type plotted for the MS and HC groups.

\section{Venous Stenosis and Venous Flow in Patients with MS}

Among patients with MS, mild age differences in flow were observed $[F(1272)=11 ; P=.001 ; r=-.18, P=.03$ for type II vessels, with the effect for type I and type III being nonsignificant]. The presence of stenosis was associated with a significant overall reduction in venous flow $[F(1272)=4 ; P=.038]$. However, the main effect was qualified by a significant vessel type $X$ stenosis interaction $[F(2544)=71.23 ; P<.001]$.

Decomposition of the interaction revealed that stenosis was associated with reduced flow in the type I vessels compared with the nonstenotic cohort $[6.20 \pm 0.21 \mathrm{~mL} / \mathrm{s}$ versus $8.86 \pm 0.26$ $\mathrm{mL} / \mathrm{s} ; F(1272)=68 ; P<.001]$. In contrast, patients with MS with stenosis had increased flow in the type II vessels $[2.79 \pm 0.14 \mathrm{~mL} / \mathrm{s}$ versus $1.08 \pm 0.17 \mathrm{~mL} / \mathrm{s} ; F(1272)=67 ; P<.001]$. A smaller but significant increase in flow was observed in type III vessels of patients with stenosis $[1.37 \pm 0.089$ versus $0.99 \pm 0.11 ; F(1272)=$ $8 ; P=.005]$. No effects of MS subtype were observed [main effect $F(2221)=1$, nonsignificant; all interactions $F<1$ ]. Fig 3 details the mean total flows for nonstenotic-MS, stenotic-MS, and HC groups.

\section{DISCUSSION}

The main finding in this study is that in patients with MS compared with HCs, venous flow is reduced in the IJV but increased in the paraspinal and other collateral veins. Moreover, in patients with MS, the presence of visible structural abnormalities, such as venous stenosis, is associated with a further decrease in jugular flow and an increase in drainage through the collateral veins.

Under normal physiologic conditions, encephalic drainage depends on body position. In the supine position, the IJVs drain most of the venous blood, ${ }^{17-20}$ whereas in the upright position, the paraspinal vessels assume more of this role. ${ }^{21-23}$ The IJVs merge with the subclavian vein to form the brachiocephalic vein, which drains the venous blood back to the heart. Along the way, several tributaries may enter the IJVs at the cervical level. The collateral veins' primary function is to augment venous drainage. The findings in this study suggest that blood may be draining via anastomosis through such structures as the anterior 


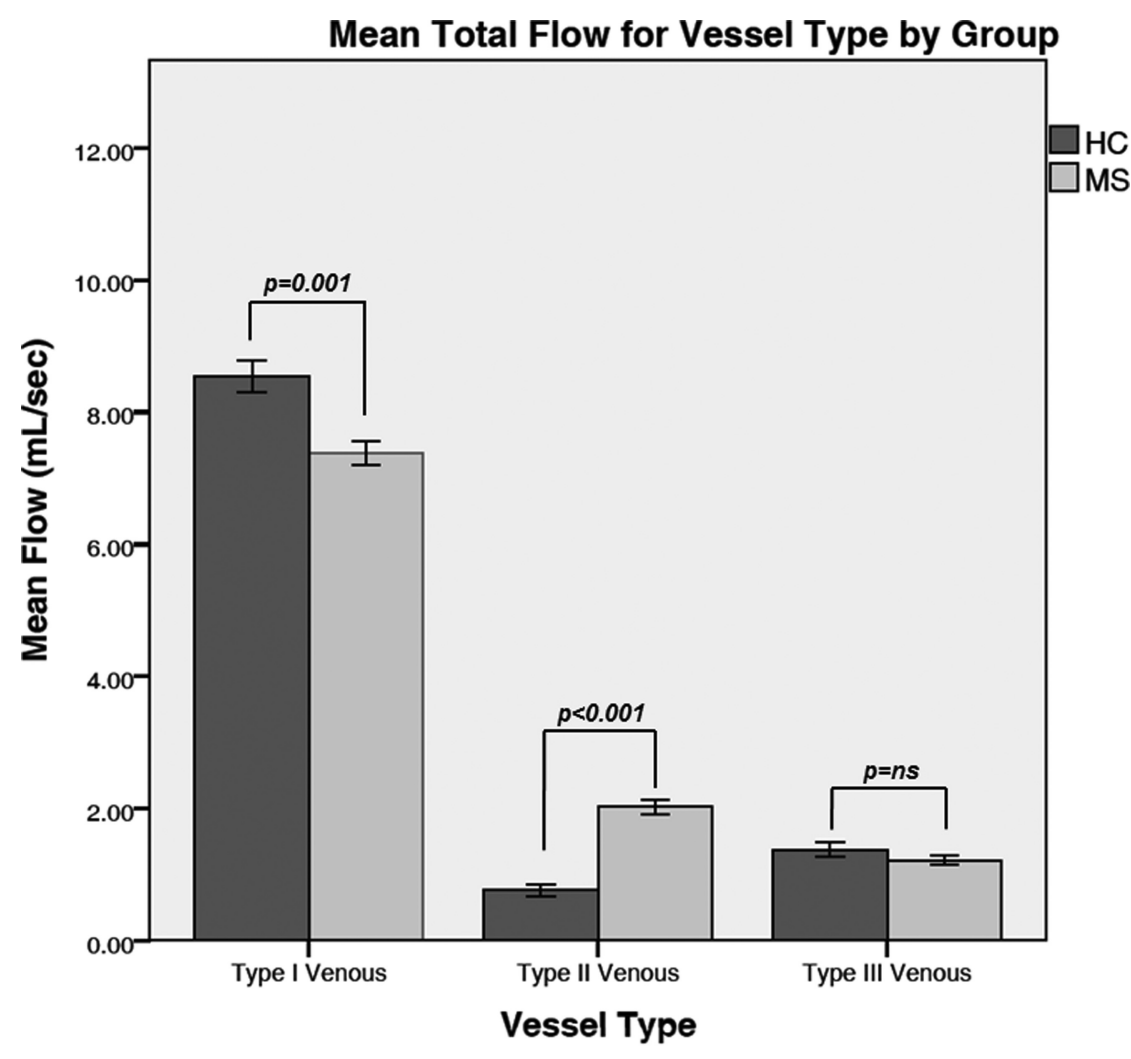

Error Bars: +/- $1 \mathrm{SE}$

FIG 2. Comparison of total mean flows $(\mathrm{mL} / \mathrm{s})$ for vessel types between diagnostic groups. The error bars represent standard errors of the mean.

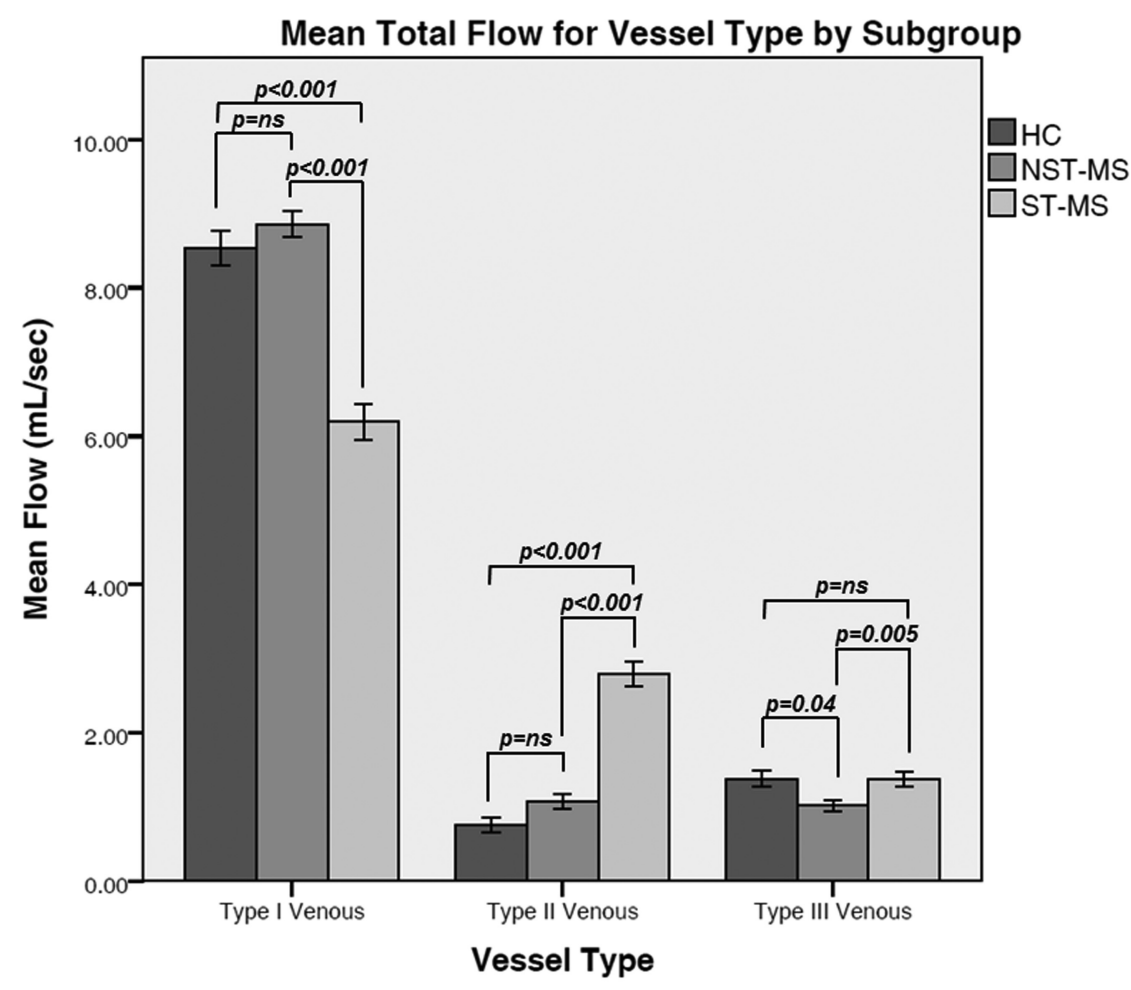

Error Bars: +/- $1 \mathrm{SE}$

FIG 3. Comparison of total mean venous flow $(\mathrm{mL} / \mathrm{s})$ by vessel type among nonstenotic-MS (NSTMS), stenotic-MS (ST-MS), and HC groups. The error bars represent standard errors of the mean. condylar confluence and into the vertebral venous system. ${ }^{24}$ Increased intra-abdominal and intrathoracic pressures have also been known to shunt blood through the vertebral and epidural networks. ${ }^{25}$ Although HCs are not exempt from having stenosis, and variations have been reported in nondisease states, ${ }^{11}$ the percentage of stenotic HCs is far less (20\%) than the percentage of stenotic patients with MS (55\%; $P<.001)$. Of note, flow in nonstenotic patients with MS is similar to HCs for all venous types, whereas stenotic patients with MS show markedly reduced IJV flow and elevated type II and III venous flow compared with nonstenotic counterparts and control patients. Although our method has been consistent in predicting jugular stenosis and resultant outflows, it is uncertain whether altered venous outflow stems from the disease or some other cause.

Our results are in accord with the findings of McTaggart et al, ${ }^{9}$ who showed greater IJV flattening and a trend toward venous collaterals specifically in MS compared with HCs. They have, however, used TOF and time-resolved imaging of contrast kinetics MRV without quantifying the flow. Using a fixed CSA as well as quantitative flow measurement, as reported here, removes the subjectivity of a nominal assessment. A pilot study by Zamboni et $\mathrm{al}^{26}$ also showed that HCs tend to drain blood via the IJVs as opposed to collaterals. Torres et al, ${ }^{11}$ however, found that the recruitment of extracranial veins as collaterals was a common finding in patients without MS by using contrast-enhanced MR angiography and venography imaging. Zivadinov et $\mathrm{al}^{27}$ reported no evidence of increased collaterals in MS by using TOF and time-resolved imaging of contrast kinetics. Their method for evaluating collaterals was ordinal: any collaterals that were $>5 \mathrm{~mm}$ in diameter (or 7 $\mathrm{mm}$ for the segment of the inferior segment of the external jugular vein) were noted as prominent. This shows that anatomic assessment alone is not enough to show differences between patients with MS and HCs and may provide an incomplete picture of the cerebral hemodynamics. 
In contrast with recent studies that used a percentage method for assessing jugular stenosis, we used an absolute threshold for the CSA measurement. ${ }^{28,29}$ We posit that the percentage method is limited because of the variation in IJV size and shape and its venous tributaries, as well as its compliance, sometimes manifesting as pinpoints, elliptic, or crescentic shapes. ${ }^{27}$ In our previous work, ${ }^{3}$ we have shown differences between the 2 methods and how using a percentage stenosis method leads to higher rates of stenosis in both HC and MS groups compared with an absolute method. A CT-based analysis of CSA that used a percentage method revealed high variability of the IJV and increasing mean CSA values along the caudal direction of the IJV. ${ }^{30}$ This vessel property served as the rationale for using absolute CSA thresholds for both the upper and lower neck levels.

An investigation of structural and functional alterations in the veins of patients with MS based on postcontrast 3D volumetric interpolated brain examination data ${ }^{31}$ revealed a high prevalence of stenosis when using a nominal assessment method. ${ }^{10} \mathrm{PC}-\mathrm{MR}$ imaging analysis of blood flow velocity demonstrated reflux. Although the authors claimed that 6 of the 28 patients had nearly completely occluded IJVs, they reported that the flow was not abnormal in these cases. This is an unusual finding given that a completely occluded vessel should have no flow. Their findings differ from ours, which suggest that the IJV morphology analysis method may affect the conclusion pertaining to the effects of morphology on venous flow.

Our findings should be interpreted in the context of several limitations. The imperfect resolution of MR imaging methods may affect the prediction of stenosis and flow. TOF and timeresolved imaging of contrast kinetics venography have been shown to have lower specificity and positive predictive value relative to catheter venography. ${ }^{32}$ The latter, while remaining the "gold standard" for assessing stenosis, is invasive, and it does not provide global and quantifiable functional information about the venous system. Moreover, MR venography methods are in good agreement with contrast venography, though MRV may have the tendency to overestimate vessel stenosis. ${ }^{10}$

The 2D PC-MR imaging flow sequence in this study is limited to capturing velocities only in the cranial and caudal directions because the data are collected in the plane perpendicular to the major arteries and veins of the neck. Advanced MR techniques such as $4 \mathrm{D}$ flow can successfully capture the spiral/vortexed flow property at the jugular bulb in persons with and without luminal irregularities. ${ }^{33}$ In a recent study, ${ }^{34}$ the application of a $4 \mathrm{D}$ flow technique combined with 3D contrast-enhanced MRA and Doppler sonography was used to evaluate venous structure and function in MS and other neurologic diseases. In that study, only a small group of participants met the criterion of chronic cerebrospinal venous insufficiency, with patients and HCs equally represented. The authors also concluded that a small amount of reflux in the cerebrospinal venous system may be a normal variant. ${ }^{34}$ Although these findings are discordant with ours, the study suffers from 2 notable drawbacks: the low intraobserver agreement when using 3D MRA to assess venous stenosis and the large age ranges used in their group comparisons yielding high variability in the flow estimates. Although 4D flow MR imaging enables diverse velocity field-based analyses, it is limited by low spatial and temporal resolution, systematic errors and noise, and the inability to resolve instantaneous and small-scale velocities. ${ }^{33}$ Further improvements in the reliability and validity of this promising approach are needed before these discrepancies can be resolved.

Morphologic IJV changes may also be due to several other factors: head and neck position, intrathoracic pressure, extrinsic compression from the coil, and swallowing movement artifacts. ${ }^{27}$ Small arteries and venules are difficult to measure when using PC-MR imaging, so it is not certain how the microvasculature is affected by a primary venous stenosis. Moreover, age, sex, hand side, and body mass index have been shown to affect IJV CSA ${ }^{35,36}$; our stenosis criteria measurement did not account for those factors. Recent semiautomatic estimation of IJV calibers at all neck levels reported $37.47 \pm 19.00 \mathrm{~mm}^{2}$ for the left IJV and $45.03 \pm$ $21.86 \mathrm{~mm}^{2}$ for the right IJV at the C2 level. ${ }^{37}$ At $70 \%$ stenosis, this would be a CSA of $11.24 \mathrm{~mm}^{2}$ and $13.5 \mathrm{~mm}^{2}$, respectively, which lends further credence to our initial upper neck level threshold of $12.5 \mathrm{~mm}^{2}$. Buch et al, ${ }^{30}$ while reporting normal variations in the caliber of IJVs in patients with MS and HCs, noted a C1 neck level average CSA of $47.7 \pm 24.8 \mathrm{~mm}^{2}$ and $66.0 \pm 29.7 \mathrm{~mm}^{2}$ for the left and right IJVs, respectively; $70 \%$ of these values would be 14.3 $\mathrm{mm}^{2}$ and $19.8 \mathrm{~mm}^{2}$, which lends further credence to our initial upper neck level threshold of $12.5 \mathrm{~mm}^{2}$. Future studies should use the aforementioned indices when diagnosing for venous stenosis. Because the HC data were pooled from multiple studies at the same imaging center, 46 of the HCs lacked anatomic venographic imaging because it was not included for that particular study. On the other hand, the flow measurements from that study helped increase the statistical power of the analysis. Future studies should include additional HCs to allow for the comparison of a higher percentage of stenotic cases with the other subgroups. Last, the comparison of MRV findings should be interpreted with caution because the groups that did have venography were not agematched, which may skew the results because of the younger age of the HC group because age has been correlated with CSA for all cervical levels. ${ }^{35,36}$

\section{CONCLUSIONS}

PC-MR imaging is a viable method for quantifying the extent of compensation in the extracranial venous system in MS and has demonstrated an increase in collateral flow caused by the presence of jugular stenosis. It is possible that this increase in collateral drainage is a compensatory response in the MS-affected brain to reduction of the IJV flow.

\section{ACKNOWLEDGMENTS}

The authors would like to thank Magnetic Resonance Innovations, Inc. - India for their assistance in data processing and Dr. Phillip Levy for usage of healthy control data.

Disclosures: Sean K. Sethi-UNRELATED: Employment: Magnetic Resonance Innovations, Inc., Comments: part-time employment for MR sequence and software development. David T. Utriainen—UNRELATED: Employment: Magnetic Resonance Innovations, Inc., Comments: half-time employee. Jing Jiang_UNRELATED: Employment: Full-time employment at Magnetic Resonance Innovations, Inc, as a software developer. Naftali Raz - RELATED: Grant: National Institutes of Health/National Institute on Aging*; Consulting Fee or Honorarium: National Institutes of Health, Comments: study section (grant reviews); Other: National Institutes of Health, Comments: grant review panel. E. Mark Haacke-UNRELATED: Board Membership: Magnetic Reso- 
nance Innovations, Inc., MR Innovations Inc., and The Magnetic Resonance Imaging Institute for Biomedical Research; Employment: MR Innovations. *Money paid to the institution.

\section{REFERENCES}

1. Compston A, Coles A. Multiple sclerosis. Lancet 2008;372:1502-17 CrossRef Medline

2. Haacke EM, Sethi SK, Jiang J, et al. The role of magnetic resonance imaging in assessing venous vascular abnormalities in the head and neck: a demonstration of cerebrospinal venous insufficiency in a subset of multiple sclerosis patients. Veins Lymphatics 2015;4: 5012-20 CrossRef

3. Sethi SK, Utriainen DT, Daugherty AM, et al. Jugular venous flow abnormalities in multiple sclerosis patients compared to normal controls. J Neuroimaging 2015;25:600-07 CrossRef Medline

4. Raz N, Daugherty AM, Sethi SK, et al. Age differences in arterial and venous extra-cerebral blood flow in healthy adults: contributions of vascular risk factors and genetic variants. Brain Struct Funct 2017 Jan 24. [Epub ahead of print] CrossRef Medline

5. Feng W, Utriainen D, Trifan G, et al. Characteristics of flow through the internal jugular veins at cervical $\mathrm{C} 2 / \mathrm{C} 3$ and $\mathrm{C} 5 / \mathrm{C} 6$ levels for multiple sclerosis patients using MR phase contrast imaging. $\mathrm{Neu}$ rol Res 2012;34:802-09 CrossRef Medline

6. Feng W, Utriainen D, Trifan G, et al. Quantitative flow measurements in the internal jugular veins of multiple sclerosis patients using magnetic resonance imaging. Rev Recent Clin Trials 2012;7: 117-26 CrossRef Medline

7. Haacke EM, Feng W, Utriainen D, et al. Patients with multiple sclerosis with structural venous abnormalities on MR imaging exhibit an abnormal flow distribution of the internal jugular veins. J Vasc Interv Radiol 2012;23:60-68.e1-3 CrossRef Medline

8. Zivadinov R, Chung CP. Potential involvement of the extracranial venous system in central nervous system disorders and aging. $B M C$ Med 2013;11:260 CrossRef Medline

9. McTaggart RA, Fischbein NJ, Elkins CJ, et al. Extracranial venous drainage patterns in patients with multiple sclerosis and healthy controls. AJNR Am J Neuroradiol 2012;33:1615-20 CrossRef Medline

10. Zaharchuk G, Fischbein NJ, Rosenberg J, et al. Comparison of MR and contrast venography of the cervical venous system in multiple sclerosis. AJNR Am J Neuroradiol 2011;32:1482-89 CrossRef Medline

11. Torres C, Hogan M, Patro S, et al. Extracranial venous abnormalities: a true pathological finding in patients with multiple sclerosis or an anatomical variant? Eur Radiol 2017;27: 239-46 CrossRef Medline

12. Pacurar EE, Sethi SK, Habib C, et al. Database integration of protocol-specific neurological imaging datasets. Neuroimage 2016;124: 1220-24 CrossRef Medline

13. Furukawa S, Nakagawa T, Sakaguchi I, et al. The diameter of the internal jugular vein studied by autopsy. Rom J Legal Med 2010;18: 125-28 CrossRef

14. Tartière D, Seguin P, Juhel C, et al. Estimation of the diameter and cross-sectional area of the internal jugular veins in adult patients. Crit Care 2009;13:R197 CrossRef Medline

15. Jiang J, Kokeny P, Ying W, et al. Quantifying errors in flow measurement using phase contrast magnetic resonance imaging: comparison of several boundary detection methods. Magn Reson Imaging 2015;33:185-93 CrossRef Medline

16. Shrout PE, Fleiss JL. Intraclass correlations: uses in assessing rater reliability. Psychol Bull 1979;86:420-28 CrossRef Medline

17. Schreiber SJ, Lurtzing F, Gotze R, et al. Extrajugular pathways of human cerebral venous blood drainage assessed by duplex ultrasound. J Appl Physiol (1985) 2003;94:1802-05 CrossRef Medline

18. Nylin G, Hedlund S, Regnstrom O. Studies of the cerebral circula- tion with labeled erythrocytes in healthy man. Circ Res 1961;9: 664-74 CrossRef Medline

19. Shenkin HA, Scheuerman WG, Spitz EB, et al. The effects of change of position upon the cerebral circulation of man. Am J Med Sci 1948; 216:714 Medline

20. Wilson EM, Halsey JH Jr., Vitek JJ. Validation of jugular venous flow as an index of total cerebral blood flow. Stroke 1972;3:300-21 CrossRef Medline

21. Valdueza JM, von Munster T, Hoffman O, et al. Postural dependency of the cerebral venous outflow. Lancet 2000;355:200-01 CrossRef Medline

22. Doepp F, Schreiber SJ, von Münster T, et al. How does the blood leave the brain? A systematic ultrasound analysis of cerebral venous drainage patterns. Neuroradiology 2004;46:565-70 CrossRef Medline

23. Menegatti E, Zamboni P. Doppler haemodynamics of cerebral venous return. Curr Neurovasc Res 2008;5:260-65 CrossRef Medline

24. San Millán Ruíz D, Gailloud P, Rüfenacht DA, et al. The craniocervical venous system in relation to cerebral venous drainage. $A J N R$ Am J Neuroradiol 2002;23:1500-08 Medline

25. Schaller B. Physiology of cerebral venous blood flow: from experimental data in animals to normal function in humans. Brain Res Brain Res Rev 2004;46:243-60 CrossRef Medline

26. Zamboni P, Sisini F, Menegatti E, et al. An ultrasound model to calculate the brain blood outflow through collateral vessels: a pilot study. BMC Neurol 2013;13:81 CrossRef Medline

27. Zivadinov R, Lopez-Soriano A, Weinstock-Guttman B, et al. Use of MR venography for characterization of the extracranial venous system in patients with multiple sclerosis and healthy control subjects. Radiology 2011;258:562-70 CrossRef Medline

28. Traboulsee AL, Knox KB, Machan L, et al. Prevalence of extracranial venous narrowing on catheter venography in people with multiple sclerosis, their siblings, and unrelated healthy controls: a blinded, case-control study. Lancet 2014;383:138-45 CrossRef Medline

29. Martin N, Traboulsee AL, Machan L, et al. Prevalence of extracranial venous narrowing on magnetic resonance venography is similar in people with multiple sclerosis, their siblings, and unrelated healthy controls: a blinded, case-control study. Can Assoc Radiol J 2017;68: 202-09 CrossRef Medline

30. Buch K, Groller R, Nadgir RN, et al. Variability in the cross-sectional area and narrowing of the internal jugular vein in patients without multiple sclerosis. AJR Am J Roentgenol 2016;206:1082-86 CrossRef Medline

31. Raz E, Pontecorvo S, Barra V, et al. MR venography in patients with multiple sclerosis and correlation with clinical and MRI parameters. J Neuroimaging 2014;24:492-97 CrossRef Medline

32. Zivadinov R, Galeotti R, Hojnacki D, et al. Value of MR venography for detection of internal jugular vein anomalies in multiple sclerosis: a pilot longitudinal study. AJNR Am J Neuroradiol 2011; 32:938-46 CrossRef Medline

33. Kefayati S, Amans M, Faraji F, et al. The manifestation of vortical and secondary flow in the cerebral venous outflow tract: an in vivo MR velocimetry study. J Biomech 2017;50:180 - 87 CrossRef Medline

34. Schrauben EM, Kohn S, Macdonald J, et al. Four-dimensional flow magnetic resonance imaging and ultrasound assessment of cerebrospinal venous flow in multiple sclerosis patients and controls. J Cereb Blood Flow Metab 2017;37:1483-93 CrossRef Medline

35. Magnano C, Belov $\mathrm{P}$, Krawiecki J, et al. Internal jugular vein narrowing and body mass index in healthy individuals and multiple sclerosis patients. Veins Lymphatics 2014;3:89-92

36. Magnano C, Belov $\mathrm{P}$, Krawiecki J, et al. Internal jugular vein crosssectional area enlargement is associated with aging in healthy individuals. PLoS One 2016;11:e0149532 CrossRef Medline

37. Laganà MM, Pelizzari L, Scaccianoce E, et al. Assessment of internal jugular vein size in healthy subjects with magnetic resonance and semiautomatic processing. Behav Neurol 2016;2016:9717210 CrossRef Medline 